\title{
Lithium phosphonate umpolung catalysts: Do fluoro substituents increase the catalytic activity?
}

\author{
Anca Gliga, Bernd Goldfuss ${ }^{*}$ and Jörg M. Neudörfl
}

\begin{abstract}
Fluorinated and nonfluorinated phosphonates are employed as precatalysts in lithium phosphonate catalyzed cross benzoin couplings. Surprisingly, a decreased catalytic activity for the fluorinated precatalysts compared to the nonfluorinated systems is observed. Furthermore, the ring size of six, seven and nine membered ring catalysts appears not to be crucial for their catalytic activity.
\end{abstract}

\section{Introduction}

Since the discovery of the cyanide catalyzed benzoin reaction by Liebig and Wöhler in 1832 [1], acyloin-type reactions evolved as powerful tools for couplings of acylanion equivalents with carbon electrophiles. In addition to cyanide [2-5] and nucleophilic carbene catalysts (e.g. thiazolium salts) [6-17], lithium phosphonates were found to catalyze cross acyloin type couplings of acylsilanes with aldehydes [18]. The catalytic cycle proposed by Johnson et al. [18] (Scheme 1) suggests that a potential metallophosphonate catalyst must act as a nucleophile, an anion ( $\mathrm{d}^{1}$-synthon) stabilization group, and as well as a leaving group (nucleofuge). Comparative computational assessments of carbanionic $\mathrm{d}^{1}$-species, which have been proposed as crucial intermediates according to the Lapworth and Breslow mechanisms, show comparable activities for lithium phosphonate and cyanide $[19,20]$.

Recently, we introduced fenchol based phosphonates as precatalysts, which are similarly accessible as fencholate metal catalysts [21-25], in the benzoin coupling (Scheme 2) [26]. A strong increase of the catalytic activity was observed for a benzylic fencholate, when the benzylic positions were occupied by $\mathrm{CF}_{3}-$ groups (92\% versus $19 \%$ yield, Scheme 2) [26]. This increased reactivity is thought to arise from a favored formation of the carbanionic $\mathrm{d}^{1}$-synthon intermediate, due to the electron withdrawing effect of the $\mathrm{CF}_{3}$ groups. A comparison of fluorinated and nonfluorinated TADDOL phosphonates (which were used

\author{
Beilstein J. Org. Chem. 2011, 7, 1189-1197. \\ doi:10.3762/bjoc. 7.138 \\ Received: 09 June 2011 \\ Accepted: 17 August 2011 \\ Published: 31 August 2011 \\ Associate Editor: M. Rueping \\ (c) 2011 Gliga et al; licensee Beilstein-Institut. \\ License and terms: see end of document.
}




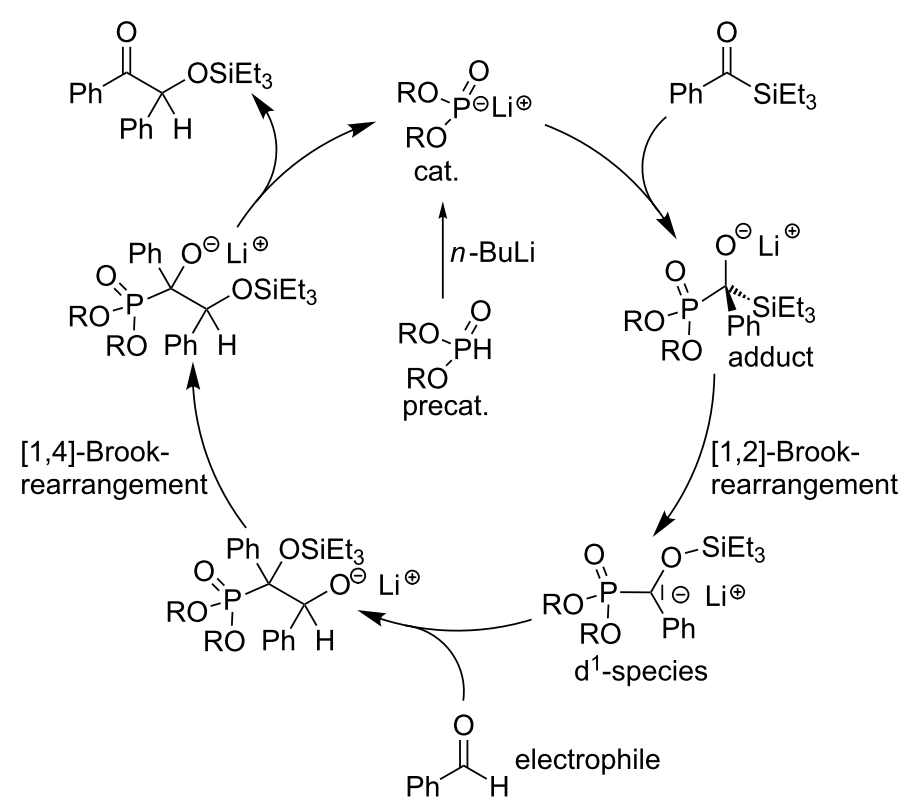

Scheme 1: Proposed catalytic cycle of the lithium phosphonate catalyzed cross benzoin coupling [18].

by Johnson's group) as precatalysts in benzoin coupling does not show any difference in reactivity (Scheme 2). In contrast the enantioselectivity is clearly higher with the fluorinated TADDOL precatalyst (Scheme 2).

Here, we analyze the effect of fluoro substituents on the catalytic activity by using different fluorinated and nonfluorinated phosphonates as precatalysts in the benzoin coupling.

\section{Results and Discussion}

As precursors for six, seven and nine membered ring phosphonates, diols 1-4, and 6-8 were synthesized (Scheme 3 ). The synthesis of diol 1 was conducted by an ortho lithiation of 1,1,1,3,3,3-hexafluoro-2-phenylpropan-2-ol and subsequent addition of the in situ generated carbanion to formaldehyde. For comparison, a nonfluorinated diol precursor 2 was synthesized. Diol 3 was used as the precursor to investigate the influence of aromatic fluoro substituents. Six ring phosphonates were real- ized with diol 4 [27] and the analogous nonfluorinated 2-(hydroxymethyl)phenol (5) as precursor.

Biphenyl-based fluorinated and nonfluorinated systems (6 [2830 ], 7 and 8 , Scheme 3) were chosen as precursors for the synthesis of nine ring phosphonates. The synthesis of these diols was realized by a double ortho lithiation of biphenyl and subsequent addition to the corresponding carbonyl compound. By this procedure, two asymmetric carbon centres and a chiral axis, which is fixed by intramolecular hydrogen bonds (6: Intramolecular O1-O2 distance $2.83 \AA$, 7: Intramolecular O1-O2 distance $2.81 \AA$, Figure 1 and Figure 2, respectively), are generated. Chiral HPLC and X-ray analyses revealed one pair of enantiomers for diol 6 and 7 (HPLC (Daicel-OD-H, 90:10 $n$-hexane/isopropanol; flow $0.5 \mathrm{~mL} / \mathrm{min}): 6: t_{\mathrm{R} 1}=10.4 \mathrm{~min} ; t_{\mathrm{R} 2}$ $=13.2 \mathrm{~min}$ (racemate); $7: t_{\mathrm{R}}=22.1 \mathrm{~min}$; X-ray structures shown in Figure 1 and Figure 2, respectively) and an additional meso product for diol 8 (HPLC: $t_{\mathrm{R} 2}=22.4 \mathrm{~min} ; t_{\mathrm{R} 3}=30.6 \mathrm{~min}$ (race-

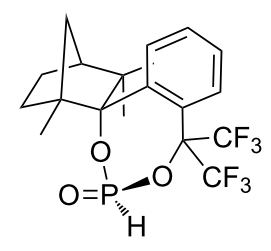

yield up to $92 \%$ ee up to $18 \%$

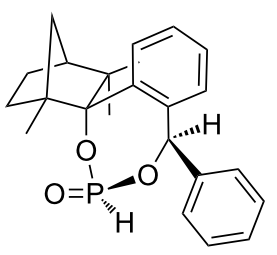

yield up to $30 \%$ ee up to $54 \%$

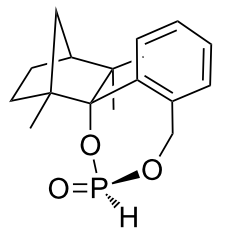

yield up to $19 \%$ ee up to $26 \%$

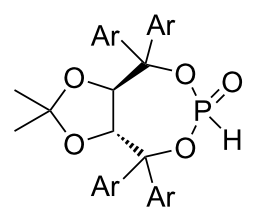

$\mathrm{Ar}=2-\mathrm{F}-\mathrm{Ph}$

conversion up to $100 \%$ ee up to $90 \%$

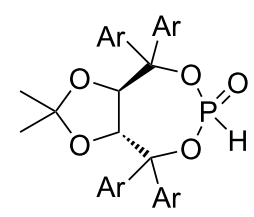

$\mathrm{Ar}=\mathrm{Ph}$

conversion up to $100 \%$ ee up to $41 \%$ 

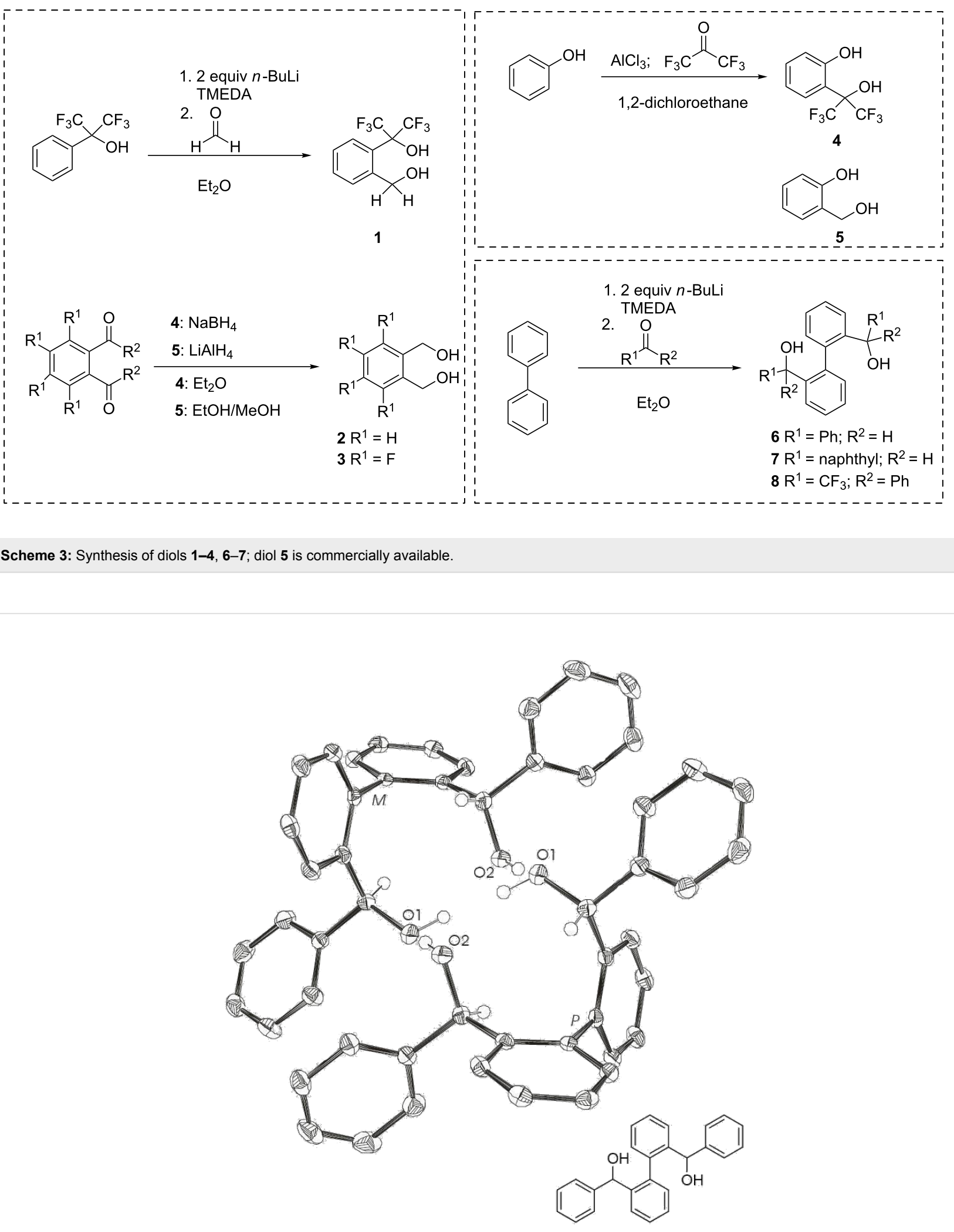

Figure 1: X-ray crystal structure of 6. $(M)-(S, S)$ and $(P)-(R, R)$ pair of enantiomers; intermolecular O1-O2 distance 2.81 $\AA$; intramolecular O1-O2 distance $2.83 \AA$. Ellipsoids correspond to $50 \%$ probability levels. Hydrogen atoms are omitted for clarity. 

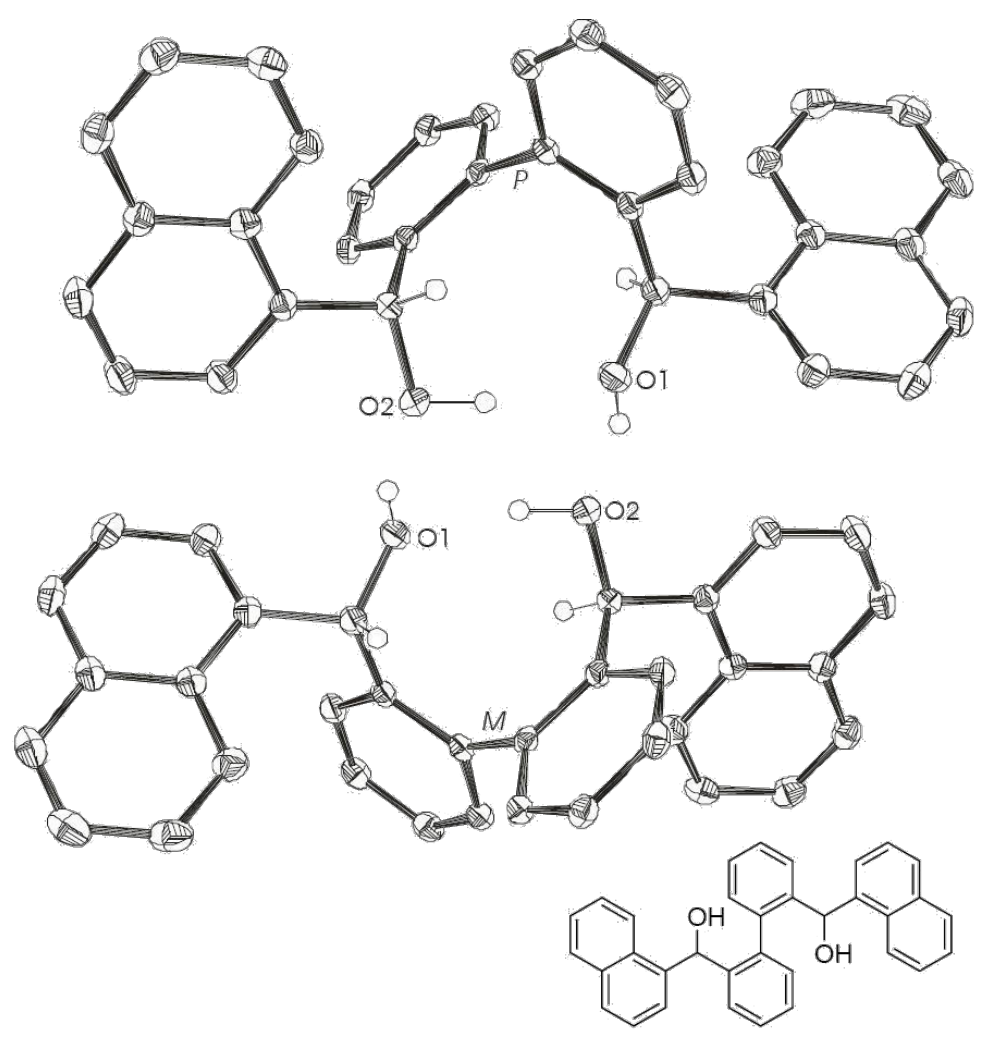

Figure 2: X-ray crystal structure of 7. $(M)-(S, S)$ and $(P)-(R, R)$ pair of enantiomers; intermolecular O1-O2 distance $2.80 \AA$; intramolecular O1-O2 distance $2.81 \AA$. Ellipsoids correspond to $50 \%$ probability levels. Hydrogen atoms are omitted for clarity.

mate); $\left.t_{\mathrm{R} 1}=9.1 \mathrm{~min}\right)$. A dimer associated by a hydrogen bond is apparent for the enantiomeric pair (6: intermolecular $\mathrm{O} 1-\mathrm{O} 2$ distance $2.81 \AA, 7$ : intermolecular O1-O2 distance $2.80 \AA$, Figure 1 and Figure 2, respectively). The favored formed enantiomeric pair has the same configuration $(R, R$ or $S, S)$ for both benzylic carbon centres, which defines the conformation of the biphenyl axis (M(inus) for $S, S$ and $P(l u s)$ for $R, R$ ).
The conformational stability of the biphenyl axis can be demonstrated by the energy difference of the optimized structures (B3LYP 6-31G*) (Table 1) (between $(M)-(S, S) ;(P)-(R, R)$ and $(P)-(S, S)$; $(M)-(R, R)$ for $6 E_{\mathrm{rel}}=3.6 \mathrm{kcal} / \mathrm{mol}$; for $7 E_{\mathrm{rel}}=4.3$ $\mathrm{kcal} / \mathrm{mol})$. The alternative diastereomers, with different configurations at the benzylic carbon $(M)-(R, S)$; $(P)-(R, S)$, are energetically disfavored (Table 1). For these diastereomers two possible

Table 1: Optimized structures of diols 6 and 7.

diol 6

\begin{tabular}{|c|c|c|c|c|}
\hline diastereomer & $(M)-(S, S) ;(P)-(R, R)$ & $(P)-(S, S) ;(M)-(R, R)$ & $\begin{array}{l}(M)-(R, S) \\
(P)-(R, S) \\
R \rightarrow S^{\mathrm{a}}\end{array}$ & $\begin{array}{l}(M)-(R, S) ; \\
(P)-(R, S) \\
S \rightarrow R^{\mathrm{a}}\end{array}$ \\
\hline$E_{\mathrm{rel}}[\mathrm{kcal} / \mathrm{mol}]^{\mathrm{b}}$ & 0 & +3.6 & +1.8 & +1.4 \\
\hline
\end{tabular}

diol 7

\begin{tabular}{|c|c|c|c|c|}
\hline diastereomer & $(M)-(S, S) ;(P)-(R, R)$ & $(P)-(S, S) ;(M)-(R, R)$ & $\begin{array}{l}(M)-(R, S) \\
(P)-(R, S) \\
R \rightarrow S^{a}\end{array}$ & $\begin{array}{l}M)-(R, S) ; \\
(P)-(R, S) \\
S \rightarrow R^{a}\end{array}$ \\
\hline$E_{\text {rel }}[\mathrm{kcal} / \mathrm{mol}]^{\mathrm{b}}$ & 0 & +4.3 & +4.4 & +4.7 \\
\hline
\end{tabular}

aDirection of hydrogen bond; 'BB3LYP 6-31G*. 
directions of the hydrogen bond were considered, that is $(M)$ $(R, S)$; $(P)-(R, S)$ with the hydrogen bond from $S \rightarrow R$ giving $E_{\text {rel }}$ $=1.4 \mathrm{kcal} / \mathrm{mol}$ and $(M)-(R, S) ;(P)-(R, S)$ with the hydrogen bond from $R \rightarrow S$ giving $E_{\text {rel }}=1.8 \mathrm{kcal} / \mathrm{mol}$ for 6; equivalently $E_{\text {rel }}=$ $4.7 \mathrm{kcal} / \mathrm{mol}$ and $E_{\text {rel }}=4.4 \mathrm{kcal} / \mathrm{mol}$ in the respective cases for 7. Similar biphenyl conformation stabilities were found for 1,1'biphenyl-2,2'-bisterpenols (terpenol moiety: (-)-Fenchol, (-)menthol, (-)-verbenol und (-)-carvol) [31,32]. The energy differences of the terpene-based conformers are between 5.1 and $5.8 \mathrm{kcal} / \mathrm{mol}[32,33]$ (B3LYP/6-31++G**:AM1).

The conversion of diols $\mathbf{1}-\mathbf{5}, \mathbf{7}$, and $\mathbf{8}$ to the desired phosphonates can be achieved by twofold addition to phosphorus trichloride and subsequent hydrolysis. Diol 6 could not be converted under the employed conditions (Scheme 4).

The strong inductive effect of the fluoro substituents is clearly visible from the ${ }^{1} J(\mathrm{P}-\mathrm{H})$ coupling constants, which are significantly increased compared to the nonfluoro-substituted phos-

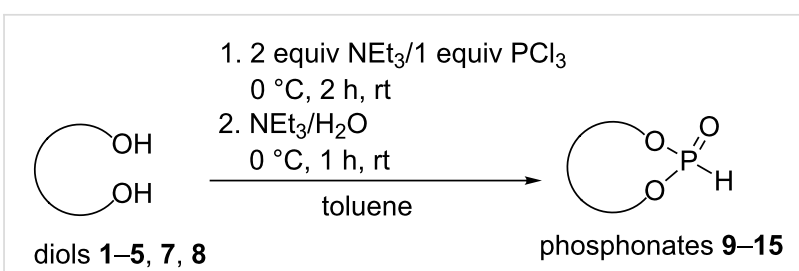

Scheme 4: Synthesis of phosphonates 9-15

phonates (Table 2). In general, ${ }^{1} J(\mathrm{P}-\mathrm{H})$ coupling constants increase with the electronegativity of the substituents [33]. The influence of electronegativity results from the change in s-character, given that the Fermi-contact is the dominant coupling mechanism [33]. According to Bent's rule [34] electron withdrawing substituents require more $\mathrm{p}$-character in the bonding orbitals, which leads to an increased s-character in the bonding $\mathrm{P}-\mathrm{H}$ orbital. The smallest influence on the coupling constant is apparent for phosphonate 11, in which the fluoro substituents are not in close proximity to the phosphorous atom (five bonds

Table 2: ${ }^{1} J(\mathrm{P}-\mathrm{H})$ coupling constants for phosphonates 9-15.

seven membered ring

${ }_{1}(\mathrm{P}-\mathrm{H})[\mathrm{Hz}] \mathrm{Phosphonate}$

six membered ring

${ }^{1} \mathrm{~J}(\mathrm{P}-\mathrm{H})[\mathrm{Hz}] \mathrm{Ph}$

nine membered ring

phosphonate

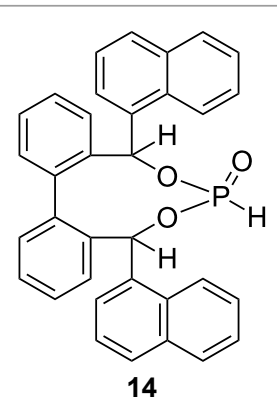

713.2

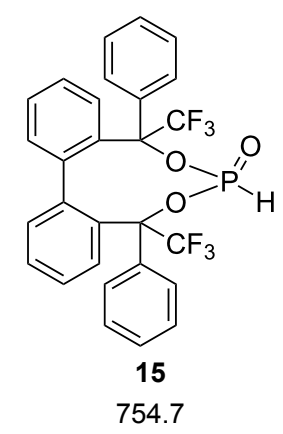


distance). The largest ${ }^{1} J(\mathrm{P}-\mathrm{H})$ coupling constant was detected for phosphonate 13. Thereby an additional electron withdrawing effect of the phenoxy group causes the further increase in the ${ }^{1} J(\mathrm{P}-\mathrm{H})$ coupling constant. All synthesized phosphonates were identified by ${ }^{31} \mathrm{P}$ NMR, especially characteristic are the phosphorus-hydrogen and phosphorus-fluoro couplings.

For phosphonates $\mathbf{1 4}$ and $\mathbf{1 5}$ (Figure 3) a doublet splitting caused by the ${ }^{1} J(\mathrm{P}-\mathrm{H})$ coupling $\sim 700 \mathrm{~Hz}$ was observed in the ${ }^{31} \mathrm{P}$ NMR spectra. The protons in the benzylic position (phosphonate 14) effect a ${ }^{3} J(\mathrm{P}-\mathrm{H})$ coupling $(12.5 \mathrm{~Hz})$ and the $\mathrm{CF}_{3}$ groups in this position (phosphonate 15) a ${ }^{4} J(\mathrm{P}-\mathrm{F})$ coupling (14.3 Hz) (Figure 3).

A crystal structure was obtained for phosphonate 15, which shows the $(M)-(R, S)$ diastereomers (Figure 4$)$.
The lithium phosphonate catalyzed benzoin reaction (Scheme 5) with phosphonates $\mathbf{9 - 1 5}$ as precatalysts led to the benzoin product in low to moderate yields (5-44\%) (Figure 5). The supposed increase in catalytic activity, which was observed for fencholbased phosphonate (Scheme 2) [21] with fluoro-substituted phosphonates as precatalysts, could not be confirmed. The highest yield was achieved with phosphonate $\mathbf{1 4}$ as precatalyst (44\%). Contrary to expectations this yield is twice as high as the yield achieved with phosphonate 15 . The reduction of the nucleophilic character of the phosphorus nucleophile in the first step of the catalytic cycle, and of the $\mathrm{d}^{1}$-synthon in the third step of the catalytic cycle (Scheme 1), could explain these results. The increased ${ }^{1} J(\mathrm{P}-\mathrm{H})$ coupling constants for the $\mathrm{CF}_{3}$ substituted phosphonates $(\mathbf{1 0}, \mathbf{1 3}, \mathbf{1 5}$, Table 2) suggest an increase in s-character at the phosphorus atom, which confirms a reduction in nucleophilic character. In contrast to the fenchol-

a)
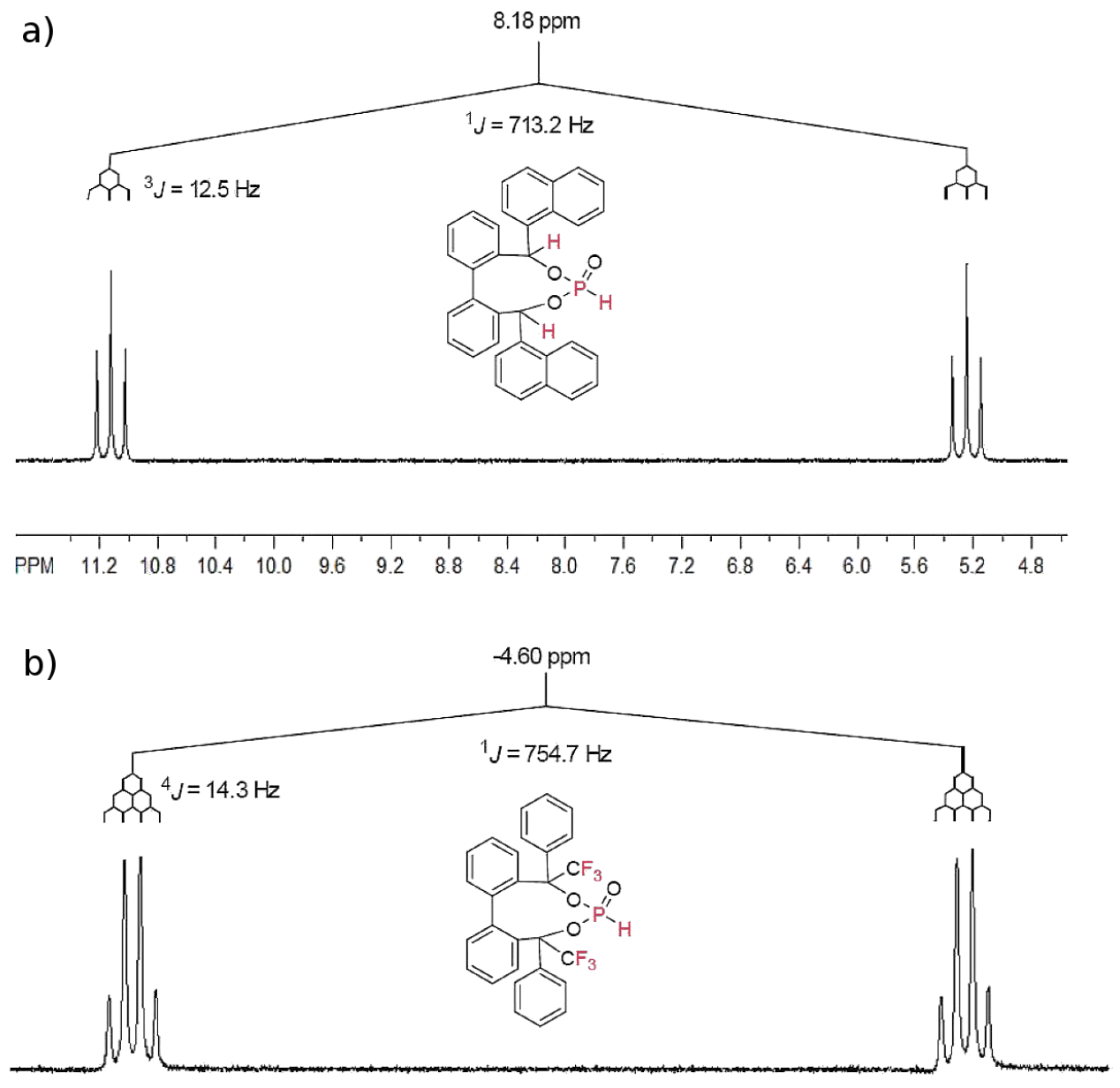

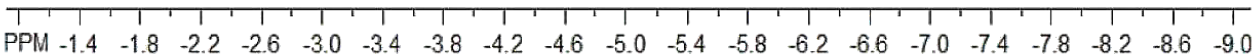




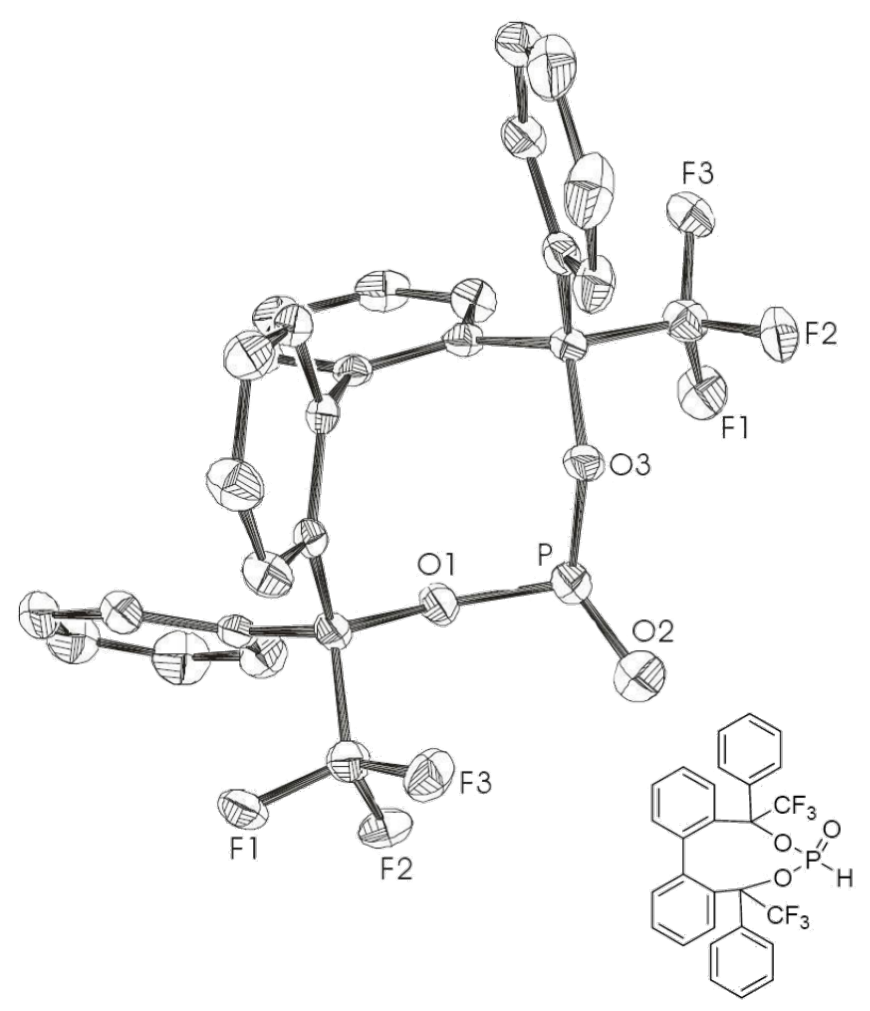

Figure 4: X-ray crystal structure of 15. $(M)-(R, S)$ diastereomer; ellipsoids correspond to $50 \%$ probability levels. Hydrogen atoms are omitted for clarity.

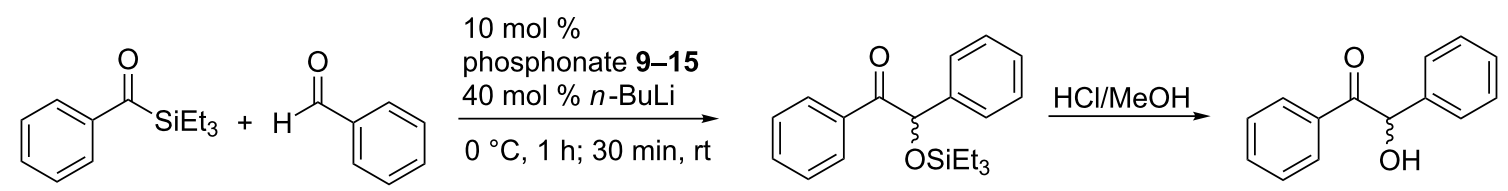

Scheme 5: Lithium phosphonate catalysts in cross benzoin coupling

based phosphonates [26] the best result was achieved by a nine membered ring phosphonate instead of a seven membered ring phosphonate. It can be concluded that the ring size is not of basic importance to the catalytic activity.

\section{Conclusion}

Three types of cyclic fluorinated and nonfluorinated phosphonates were synthesized and used as precatalysts in cross benzoin couplings with yields ranging from 5 to $44 \%$. The inductive effect of $\mathrm{CF}_{3}$ substituents in benzylic position of phosphonates $\mathbf{1 0}, 13$ and 15 gives rise to increased ${ }^{1} J(\mathrm{P}-\mathrm{H})$ couplings in $\mathrm{P}-\mathrm{H}$ precatalysts and hence points to increased s-character at the phosphorus lone pair in the active anionic catalysts [33]. A rise of catalytic activity due to the inductive effect of $\mathrm{CF}_{3}$ substituents, as was observed before for a fenchol-based phosphonate (Scheme 2) [26], was not realized with the phosphonates employed herein. Instead a reduction of catalytic activity was apparent with fluorinated phosphonates compared to the nonfluorinated phosphonates. This can be explained by a weaker nucleophilic character of the phosphorus nucleophile, as a consequence of the increased s-character. Comparisons of phosphonates with different ring sizes show that the nine ring phosphonates result in higher yields than do the six and seven ring phosphonates. 


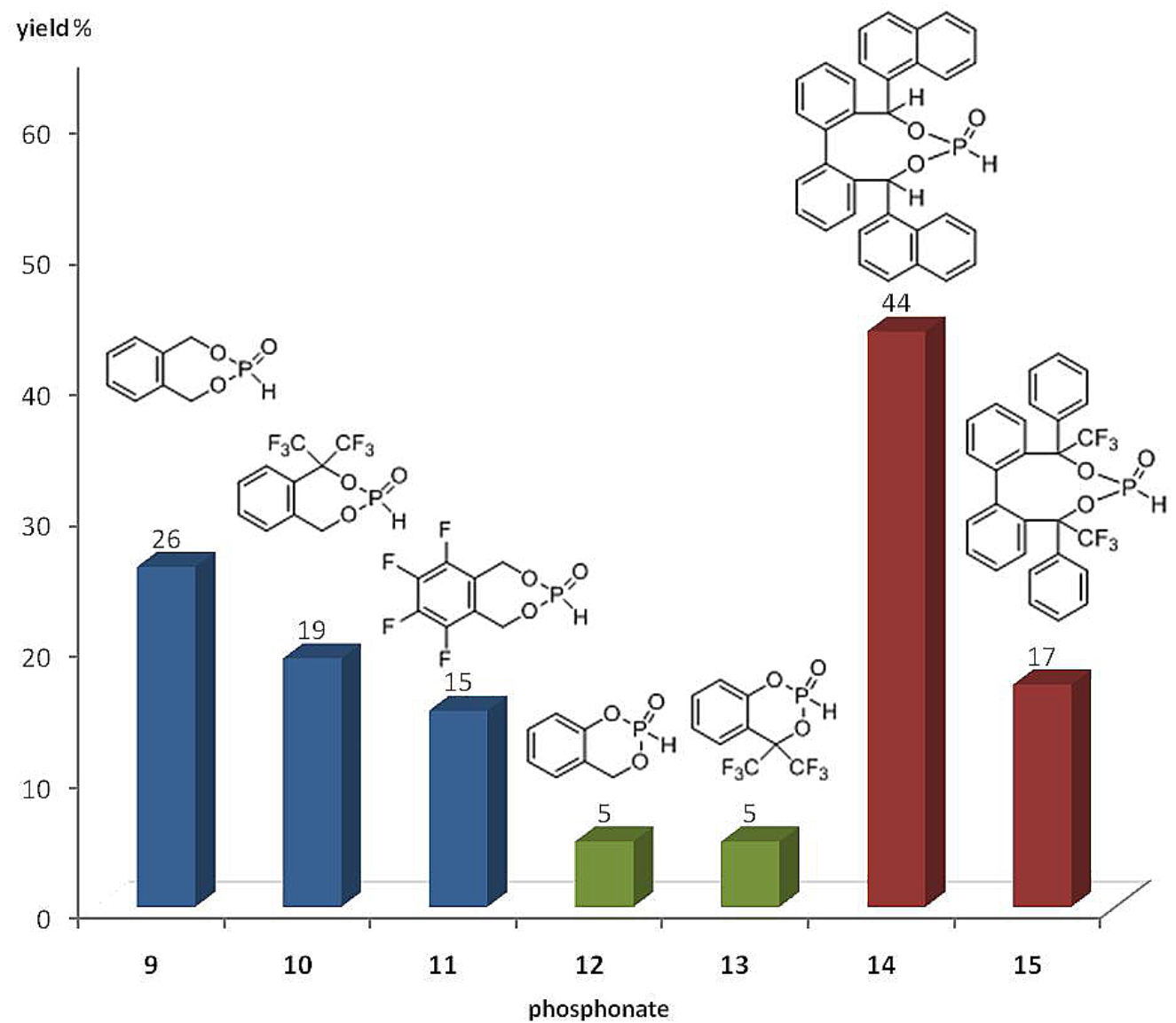

Figure 5: Phosphonate precatalysts 9-15 in cross benzoin coupling

\section{Supporting Information}

Experimental procedures, characterization data for compounds 1-4, 6-15, crystallographic data for compounds 6, 7, 15, computational details for compounds 6, 7 and general procedure for phosphonates as precatalysts in cross benzoin coupling.

\section{Supporting Information File 1}

Experimental procedure and characterization data. [http://www.beilstein-journals.org/bjoc/content/ supplementary/1860-5397-7-138-S1.pdf]

\section{Acknowledgements}

We are grateful to the Fonds der Chemischen Industrie for financial support. We especially thank the Deutsche Forschungsgemeinschaft (DFG) for funding (GO-930/9-1) as well as the Bayer AG, the BASF AG, the Wacker AG, the Evonic AG, the Raschig $\mathrm{GmbH}$, the Symrise $\mathrm{GmbH}$, the Solvay $\mathrm{GmbH}$ and the OMG group for generous support.

\section{References}

1. Wöhler, F.; von Liebig, J. Ann. Pharm. 1832, 3, 249-282. doi:10.1002/jlac. 18320030302

2. Linghu, X.; Johnson, J. S. Angew. Chem. 2003, 115, 2638-2640. doi:10.1002/ange.200250554

3. Tarr, J. C.; Johnson, J. S. Org. Lett. 2009, 11, 3870-3873. doi:10.1021/ol901314w

4. Bausch, C. C.; Johnson, J. S. Adv. Synth. Catal. 2005, 347, 1207-1211. doi:10.1002/adsc.200505097

5. Demir, A. S.; Reis, Ö.; İğdir, A. Ç.; Esiringü, İ.; Eymur, S. J. Org. Chem. 2005, 70, 10584-10587. doi:10.1021/jo051811u

6. Ugai, T.; Tanaka, S.; Dokawa, S. J. Pharm. Soc. Jpn. 1943, 63, 296-300.

7. Breslow, R. J. Am. Chem. Soc. 1958, 80, 3719-3726. doi:10.1021/ja01547a064

8. Sheehan, J. C.; Hunneman, D. H. J. Am. Chem. Soc. 1966, 88, 3666-3667. doi:10.1021/ja00967a049

9. Sheehan, J. C.; Hara, T. J. Org. Chem. 1974, 39, 1196-1199. doi:10.1021/jo00923a006

10. Tagaki, W.; Tamura, Y.; Yano, Y. Bull. Chem. Soc. Jpn. 1980, 53, 478-480. doi:10.1246/bcsj.53.478

11. Enders, D.; Breuer, K.; Teles, J. H. Helv. Chim. Acta 1996, 79, 1217-1221. doi:10.1002/hlca.19960790427 
12. Knight, R. L.; Leeper, F. J. J. Chem. Soc., Perkin Trans. 11998 , 1891-1894. doi:10.1039/A803635G

13. Enders, D.; Kallfass, U. Angew. Chem., Int. Ed. 2002, 41, 1743-1745. doi:10.1002/1521-3773(20020517)41:10<1743::AID-ANIE1743>3.0.CO ;2-Q

14. Enders, D.; Niemeier, O. Angew. Chem., Int. Ed. 2006, 118, 1491-1495. doi:10.1002/anie.200503885

15. Takikawa, H.; Hachisu, Y.; Bode, J. W.; Suzuki, K. Angew. Chem., Int. Ed. 2006, 118, 3572-3574. doi:10.1002/anie.200600268

16. Enders, D.; Henseler, A. Adv. Synth. Catal. 2009, 351, 1749-1752. doi:10.1002/adsc.200900247

17. Enders, D.; Grossmann, A.; Fronert, J.; Raabe, G. Chem. Commun. 2010, 46, 6282-6284. doi:10.1039/c0cc02013c

18. Linghu, X.; Potnick, J. R.; Johnson, J. S. J. Am. Chem. Soc. 2004, 126, 3070-3071. doi:10.1021/ja0496468

19. Goldfuss, B.; Schumacher, M. J. Mol. Model. 2006, 12, 591-595. doi:10.1007/s00894-005-0036-4

20. Schumacher, M.; Goldfuss, B. Tetrahedron 2008, 64, 1648-1653. doi:10.1016/j.tet.2007.12.019

21. Steigelmann, M.; Nisar, Y.; Rominger, F.; Goldfuss, B. Chem.-Eur. J. 2002, 8, 5211-5218.

doi:10.1002/1521-3765(20021115)8:22<5211::AID-CHEM5211>3.0.C O;2-S

22. Goldfuss, B.; Steigelmann, M.; Rominger, F. Eur. J. Org. Chem. 2000, 1785-1792

doi:10.1002/(SICI)1099-0690(200005)2000:9<1785::AID-EJOC1785>3 .0.CO;2-0

23. Goldfuss, B.; Löschmann, T.; Rominger, F. Chem.-Eur. J. 2004, 10, 5422-5431. doi:10.1002/chem.200400273

24. Kop-Weiershausen, T.; Lex, J.; Neudörfl, J.-M.; Goldfuss, B. Beilstein J. Org. Chem. 2005, 1, No. 6. doi:10.1186/1860-5397-1-6

25. Goldfuss, B.; Löschmann, T.; Kop-Weiershausen, T.; Neudörfl, J.; Rominger, F. Beilstein J. Org. Chem. 2006, 2, No. 7. doi:10.1186/1860-5397-2-7

26. Gliga, A.; Klare, H.; Schumacher, M.; Soki, F.; Neudörfl, J. M.; Goldfuss, B. Eur. J. Org. Chem. 2011, 2, 256-263. doi:10.1002/ejoc.201001295

27. Nolan, B. G.; Tsujioka, S.; Strauss, S. H. J. Fluorine Chem. 2002, 118, 103-106. doi:10.1016/S0022-1139(02)00203-8

28. Bergmann, E. D.; Pelchowicz, Z. J. Org. Chem. 1954, 19, 1387-1390. doi:10.1021/jo01373a024

29. Weitzberg, M.; Abu-Shakra, E.; Azeb, A.; Aizenshtat, Z.; Blum, J. J. Org. Chem. 1987, 52, 529-536. doi:10.1021/jo00380a010

30. Tsantrizos, Y. S.; Folkins, P. L.; Britten, J. F.; Harpp, D. N.; Ogilvie, K. K. Can. J. Chem. 1992, 70, 158-164. doi:10.1139/v92-026

31. Goldfuss, B.; Rominger, F. Tetrahedron 2000, 56, 881-884. doi:10.1016/S0040-4020(99)01077-7

32. Alpagut, Y.; Goldfuss, B.; Neudörfel, J.-M. Beilstein J. Org. Chem. 2008, 4, No. 25. doi:10.3762/bjoc. 4.25

33. Berger, S.; Braun, S.; Kalinowski, H.-O. NMR-Spektroskopie von Nichtmetallen Band 3. Thieme: Stuttgart, Germany, 1993; pp 121-122.

34. Bent, H. A. Chem. Rev. 1961, 61, 275-311. doi:10.1021/cr60211a005

\section{License and Terms}

This is an Open Access article under the terms of the Creative Commons Attribution License

(http://creativecommons.org/licenses/by/2.0), which permits unrestricted use, distribution, and reproduction in any medium, provided the original work is properly cited.

The license is subject to the Beilstein Journal of Organic Chemistry terms and conditions:

(http://www.beilstein-journals.org/bjoc)

The definitive version of this article is the electronic one which can be found at:

doi:10.3762/bjoc. 7.138 